\title{
Qualidade nutricional de goiabas submetidas aos processos de desidratação por imersão-impregnação e secagem complementar por convecção
}

\author{
Nutritional quality of osmo-convective dried guavas
}

\author{
Valéria Aparecida Vieira QUEIROZ ${ }^{1}$, Pedro Amorim BERBERT ${ }^{2 *}$, Marília Amorim Berbert de MOLINA ${ }^{3}$, \\ Geraldo de Amaral GRAVINA², Luciano Rodrigues QUEIROZ", José Accácio da SILVA 5
}

\begin{abstract}
Resumo
Na desidratação por imersão-impregnação há transferência de água e de compostos naturais do produto para a solução hipertônica, porém poucos trabalhos têm sido realizados para identificar e quantificar as perdas destes compostos. Sendo assim, o presente trabalho teve por objetivo avaliar as alterações nos teores dos minerais $\mathrm{Na}, \mathrm{K}, \mathrm{Ca}, \mathrm{Mg}, \mathrm{Zn}$ e $\mathrm{Mn}$ e de vitamina $\mathrm{C}$ em goiabas submetidas aos processos combinados de desidratação por imersão-impregnação $\left(50^{\circ} \mathrm{C}\right.$ por 2 horas) e secagem por convecção até teor de água de $20 \%$ b.u. Os solutos empregados foram: a sacarose, em soluções de 0,4 e 0,5 g.mL $\mathrm{mL}^{-1}$, e o açúcar líquido invertido, em soluções a $41 \%$ (p/p) e sem diluição. Utilizouse ainda solução mista de sacarose a 0,3 g.mL $\mathrm{mL}^{-1}$ e sucralose a $0,2 \mathrm{~g} . \mathrm{L}^{-1}$, além do tratamento controle, que consistiu apenas na secagem por convecção, empregando-se um nível de temperatura e velocidade do ar de secagem, $60^{\circ} \mathrm{C}$ e $1,25 \mathrm{~m} / \mathrm{s}$, respectivamente. O efeito das condições de armazenamento sobre a estabilidade do ácido ascórbico foi avaliado sob duas temperaturas, 7 e $25^{\circ} \mathrm{C}$, durante 60 dias. Os resultados indicaram reduções de 20 a 64\% no teor de minerais ao final da desidratação por imersão-impregnação e perdas não significativas de ácido ascórbico, exceto no tratamento com açúcar invertido sem diluição. A secagem por convecção promoveu perdas significativas de vitamina $\mathrm{C}$, de 32 a $68 \%$; os valores correspondentes para as perdas de vitamina C durante o armazenamento a 7 e $25^{\circ} \mathrm{C}$ foram de 58 a $82 \%$ e de 70 a $86 \%$, respectivamente.
\end{abstract}

Palavras-chave: Psidium guajava L.; minerais; vitamina C; desidratação osmótica.

\begin{abstract}
During dewatering and impregnation soaking (DIS), transfer of water and of natural compounds from the product to the hypertonic solution occurs, however, few studies have been carried out to identify and quantify the losses of these compounds. Thus, this work reports on the losses of vitamin $\mathrm{C}$ and of the following minerals: $\mathrm{Na}, \mathrm{K}, \mathrm{Ca}, \mathrm{Mg}, \mathrm{Zn}$ and $\mathrm{Mn}$, in red guavas submitted to the combined process of DIS (at $50{ }^{\circ} \mathrm{C}$ for 2 hours) and convective drying (at $60{ }^{\circ} \mathrm{C}$ and air velocity of $1.25 \mathrm{~m} / \mathrm{s}$, to a final moisture content of $20 \%$ w.b.). Studies were carried out employing two types of solutes: sucrose (in 0.4 and $0.5 \mathrm{~g} \cdot \mathrm{mL}^{-1}$ solutions) and liquid invert sugar (in a $41 \% \mathrm{w} / \mathrm{w}$ solution and as an undiluted syrup). Also, a test was performed using a solution comprised of $0.3 \mathrm{~g} \cdot \mathrm{mL}^{-1}$ sucrose and $0.2 \mathrm{~g} . \mathrm{L}^{-1}$ sucralose. The control treatment consisted of drying guava solely in the convective drier. The effect of storage conditions on the stability of ascorbic acid was assessed after 60 days at 7 and $25^{\circ} \mathrm{C}$. Results indicated reductions in the range of 20 to $64 \%$ in the amounts of the minerals studied at the end of the DIS process, as compared to the amount found in fresh fruits, and negligible losses of vitamin $\mathrm{C}$, except in the treatment with undiluted liquid invert sugar. Convective drying promoted losses of vitamin $\mathrm{C}$ in the range of 32 to $68 \%$. The ranges of vitamin $\mathrm{C}$ loss in storage at 7 and $25{ }^{\circ} \mathrm{C}$ were 58 to $82 \%$ and 70 to $86 \%$, respectively.
\end{abstract}

Keywords: Psidium guajava L.; minerals; vitamin C; osmotic dehydration.

\section{Introdução}

Os atributos de qualidade de um alimento processado dizem respeito à sua aparência e textura, ao seu sabor e odor (flavour), ao seu valor nutritivo e à sua segurança para a saúde do consumidor (CHITARRA; CHITARRA, 1990; FELLOWS, 1994). O processamento de alimentos traz conseqüências inevitáveis ao seu valor nutricional. Macro e micronutrientes são afetados, em diferentes níveis, tanto durante o processo quanto no decorrer do período de armazenagem. O grau de estabilidade depende amplamente do tipo e da estrutura do nutriente, da

composição química do alimento e da severidade e duração do processamento. As perdas se devem à sensibilidade dos diferentes componentes ao calor, $\mathrm{pH}$, oxigênio, luz, umidade ou à combinação destes (HENRY; MASSEY, 2001; HENRY; HEPPELL, 2002).

Mais apropriadamente denominada Desidratação por Imersão-Impregnação (DII), a desidratação osmótica consiste na remoção parcial de água do alimento por meio de seu contato direto com uma solução hipertônica. É considerada uma etapa

2 Laboratório de Engenharia Agrícola, Universidade Estadual do Norte Fluminense - UENF, Av. Alberto Lamego, 2000, CEP 28013-602, Campos dos Goytacazes - RJ, Brasil, E-mail: pberbert@uenf.br

${ }^{3}$ Laboratório de Biotecnologia, Universidade Estadual do Norte Fluminense - UENF, E-mail: mberbert@uenf.br

${ }^{4}$ Universidade Estadual do Norte Fluminense - UENF

${ }^{5}$ Laboratório de Fitotecnia, Universidade Estadual do Norte Fluminense - UENF

${ }^{*}$ A quem a correspondência deve ser enviada 
de pré-tratamento que favorece a obtenção de produtos com qualidade sensorial e nutricional superior à de produtos desidratados unicamente por secagem por convecção (LAZARIDES, 1994; TORREGGIANI, 1993).

$\mathrm{Na}$ DII ocorrem três tipos de fluxo durante o período em que o alimento está imerso na solução osmótica: 1) água do produto para a solução; 2) soluto da solução para o produto; e 3) solutos naturais do produto para a solução. Este terceiro tipo de transferência de massa, embora quantitativamente negligenciável quando comparado aos outros dois, desperta interesse pela possibilidade de eventualmente afetar as características sensoriais e nutricionais do produto final (RAOULT-WACK, 1994). Segundo Dalla Rosa e Giroux (2001), embora alguns componentes de frutas e hortaliças, principalmente pigmentos, ácidos orgânicos e proteínas, sejam lixiviados para a solução durante o tratamento osmótico, poucos trabalhos têm sido realizados na tentativa de identificar e quantificar aqueles que efetivamente são perdidos para o meio osmótico.

A goiaba é uma fruta de clima tropical que se destaca por seu elevado valor nutritivo, sendo uma das melhores fontes de vitamina C, licopeno, potássio, cobre e fibras (GORINSTEIN et al., 1999; PADULA; RODRIGUEZ-AMAYA, 1986; QUEIROZ, 2004). Um único fruto de cerca de $150 \mathrm{~g}$ é capaz de suprir $100 \%$ da ingestão diária recomendada de vitamina $\mathrm{C}$ e de licopeno que, segundo o I.O.M. (1999) dos Estados Unidos, é de 90 e de 5 a $10 \mathrm{mg}$, respectivamente. Além da grande aceitação para consumo in natura, a fruta é ainda adequada à aplicação industrial por apresentar alto rendimento em polpa. Ressalta-se, entretanto, seu curto período de conservação, que implica na necessidade de rápida comercialização ou processamento póscolheita (DURIGAN, 1997).

Os minerais, apesar de constituírem apenas $4 \%$ do organismo humano, são essenciais à manutenção de várias funções de grande importância fisiológica e os resultados da ausência destes são severos no organismo humano. Além de outros, o cálcio, o sódio, o potássio e o magnésio são considerados macronutrientes e o $\mathrm{Zn}$ e o $\mathrm{Mn}$, micronutrientes (MAHAN; ESCOOTT-STUMP, 2002). O cálcio desempenha papel relevante numa série de processos fisiológicos e bioquímicos essenciais, como a coagulação sanguínea, a adesividade celular e a modulação da ação de vários hormônios. O magnésio desempenha papel relevante na transmissão do impulso nervoso e na atividade neuromuscular. O potássio participa do metabolismo de proteínas e de carboidratos e o sódio tem função importante na regulação do $\mathrm{pH}$, sendo necessário para muitos sistemas de transporte de aminoácidos, glicose e outros íons através da membrana (BRODY, 1994).

A vitamina C (ácido ascórbico) é um nutriente solúvel em água, essencial ao organismo humano. Ela desempenha grande número de funções em reações e processos celulares, atuando como cofator na biossíntese enzimática de colágeno, carnitina, catecolaminas, hormônios neuropeptídeos e ácidos biliares. Além de cofator enzimático, o ácido ascórbico age ainda no metabolismo da fenilalanina e da tirosina e nos processos de óxido-redução como na redução do $\mathrm{Fe}^{+++} \mathrm{em} \mathrm{Fe} \mathrm{F}^{++}$, aumentando assim sua biodisponibilidade na absorção intestinal (FRANCO, 2001; PADH, 1991). Uma das funções da vitamina C, que mais têm sido destacadas no momento, é a de prevenção contra os efeitos deletérios dos oxidantes, sendo capaz de reduzir as espécies reativas de oxigênio e nitrogênio em moléculas estáveis (RICHARDSON; BALL; ROSENFELD, 2002). Considera-se, geralmente, que se esta vitamina for adequadamente retida no alimento durante o processamento, outros nutrientes também serão, sendo sua presença, desta forma, considerada como um parâmetro da qualidade nutricional do alimento processado (UDDIN et al., 2002).

O presente estudo teve como objetivo avaliar as alterações nos teores de $\mathrm{Na}, \mathrm{K}, \mathrm{Ca}, \mathrm{Mg}, \mathrm{Zn}, \mathrm{Mn}$, e vitamina $\mathrm{C}$, em goiabas submetidas ao processo de desidratação por imersãoimpregnação em soluções de sacarose e de açúcar invertido e posteriormente secas por convecção. Além disso, avaliou-se o efeito da temperatura sobre a estabilidade do ácido ascórbico ao final de 60 dias de armazenamento.

\section{Material e métodos}

\subsection{Preparo das amostras}

Goiabas (Psidium guajava L.) cv Pedro Sato, provenientes de pomares comerciais localizados no Município de Cachoeiras de Macacu, RJ, foram transportadas acondicionadas em caixas térmicas para o local onde o trabalho foi realizado. Os frutos foram selecionados de acordo com os seguintes atributos: 1) estádio de maturação dois, caracterizado pela coloração verde clara da casca, ângulo de cor $\left(h^{\circ}\right)$ entre 113 e 116;2) uniformidade de tamanho, que incluiu a massa, o diâmetro transversal e o diâmetro longitudinal dos frutos; e 3 ) ausência de defeitos, que consistiu na inexistência de injúrias físicas. Os frutos selecionados foram acondicionados em bandejas plásticas e armazenados sob refrigeração, a $7^{\circ} \mathrm{C}$, até o dia da realização do experimento em câmaras do tipo B.O.D. Marconi modelo MA 415.

Ao atingir o estádio de maturação três, caracterizado pela cor verde-amarelada da casca, ângulo de cor $\left(\mathrm{h}^{\circ}\right)$ entre $109 \mathrm{e}$ 112 e antes do início de cada teste experimental, oito frutos foram retirados do ambiente de armazenamento, quatro para as análises de vitamina $\mathrm{C}$ e quatro para as de minerais, sendo em seguida lavados em água corrente e imersos em solução de detergente neutro a $1 \%$ por 15 minutos. Logo depois, foram enxaguados em água corrente, sanitizados em solução de hipoclorito de sódio a $100 \mathrm{ppm}$ por 15 minutos e secos com papel absorvente. Em seguida, os frutos foram descascados e cortados transversalmente, removendo-se as sementes e dividindo-se cada metade em outras quatro partes, de modo a obterem-se oito frações por fruto, num total de 64 amostras. Retiraram-se então oito frações, ou seja, uma amostra por fruto, para caracterização da fruta in natura, as quais foram imediatamente mergulhadas em nitrogênio líquido por 5 segundos. Em seguida essas amostras foram acondicionadas em frascos de polietileno branco fosco de $30 \mathrm{~mL}$, com tampa rosqueável, e armazenadas em freezer a $-18{ }^{\circ} \mathrm{C}$, para análises posteriores.

Para evitar o escurecimento enzimático das amostras, as 56 frações restantes, sete de cada fruto, foram branqueadas em vapor d'água por 1 minuto, sendo, em seguida, colocadas em saco plástico e imersas em banho de gelo por 1 minuto. 
As amostras utilizadas para análise de minerais foram ainda imersas em solução de ácido ascórbico 1\% por 5 minutos logo após o branqueamento. Depois dessa etapa, retirou-se mais uma fração de $1 / 8$ de cada fruto para as análises referentes ao branqueamento/imersão em ácido ascórbico, as quais foram acondicionadas conforme descrito no parágrafo anterior.

\subsection{Desidratação por imersão-impregnação (DII)}

As 48 frações restantes, sendo seis de cada goiaba, foram submetidas à desidratação por imersão-impregnação em soluções concentradas de sacarose ou açúcar invertido empregandose a relação fruta:xarope de 1:10 (p/p), em béqueres de vidro de $1.000 \mathrm{~mL}$, contendo seis frações de cada fruto. Em seguida, os béqueres foram colocados em três agitadoras-incubadoras de bancada (B.Braun Biotech modelo Certomat U/Certomat HK; Nova Ética, modelo $430 \mathrm{RDB}$ ) a $50^{\circ} \mathrm{C}$, com freqüência de agitação de $60 \mathrm{~min}^{-1}$ por 2 horas. As soluções utilizadas para a desidratação constituíram os seguintes tratamentos: sacarose a $0,5 \mathrm{~g} \cdot \mathrm{mL}^{-1}(\mathrm{~T} 1)$, sacarose a $0,4 \mathrm{~g} \cdot \mathrm{mL}^{-1}(\mathrm{~T} 2)$, mistura de sacarose a 0,3 g.mL $\mathrm{mL}^{-1}$ e sucralose a $0,2 \mathrm{~g} \cdot \mathrm{L}^{-1}$ (T3), açúcar invertido a $41 \%$ p/p (T4) e açúcar invertido sem diluição (T5). O tratamento controle (T6), em que as amostras foram secas diretamente em secador por convecção, foi aplicado apenas nos pedaços de goiaba destinados às análises de vitamina $\mathrm{C}$. Devido à possibilidade de contaminação do produto por íons metálicos eventualmente presentes no ar de secagem, o experimento para análise dos teores de minerais não prosseguiu com a etapa de secagem por convecção forçada e foi finalizado após a desidratação por imersão-impregnação.

O adoçante sucralose foi adicionado à solução de sacarose a 0,3 g.mL $\mathrm{mL}^{-1}$ numa concentração de 0,2 g. $\mathrm{L}^{-1}$ com o objetivo de se obter um produto light (redução de calorias superior a 25\%) com o mesmo nível de doçura do tratamento T2 (sacarose 0,4 g.mL $\mathrm{mL}^{-1}$ ), porém, com $30 \%$ menos caloria (tratamento T3). Adotaram-se quatro repetições por tratamento, sendo cada goiaba considerada uma repetição para as análises de vitamina $\mathrm{C} \mathrm{e}$ de minerais. Sendo assim, foram utilizadas 44 goiabas em todo o experimento.

A sacarose foi adquirida no mercado local e o xarope de açúcar invertido utilizado, Gludex 216 com taxa de inversão $\geq 90 \%$, foi fornecido pela Dulcini Alimentos. O edulcorante em pó sucralose foi obtido junto a Attivos Magisttrais. As soluções osmóticas foram preparadas com água destilada (para determinação do teor de vitamina $\mathrm{C}$ ) ou desionizada (para determinação dos teores de minerais), autoclavadas a $120^{\circ} \mathrm{C}$ por 20 minutos e estocadas sob refrigeração a $7^{\circ} \mathrm{C}$, em B.O.D., até o momento de sua utilização.

Depois da desidratação osmótica, os frutos foram enxaguados com água destilada, para remoção do filme de açúcar formado na superfície e, em seguida, envolvidos em papel absorvente para retirada do excesso de água. Depois desta etapa, foram retiradas oito amostras correspondentes a $1 / 8$ de cada fruto para as análises posteriores de vitamina $\mathrm{C}$ e minerais. As cinco frações restantes de cada fruto (20 amostras) destinadas à análise de vitamina $\mathrm{C}$ foram então submetidas à secagem por convecção.

\subsection{Secagem por conveç̧ão e armazenamento}

A segunda etapa do processo consistiu na secagem por convecção das amostras desidratadas osmoticamente, empregando para tanto um protótipo de secador do tipo gabinete com bandejas. Empregou-se apenas um nível de temperatura e velocidade do ar de secagem, $60^{\circ} \mathrm{C}$ e $1,25 \mathrm{~m} / \mathrm{s}$, respectivamente. Os testes foram interrompidos quando o teor de água do produto, determinado por gravimetria, atingiu valores entre 18 e $20 \%$ b.u. A temperatura e a umidade relativa do ar de secagem foram medidas com termo-higrômetro digital (Dwyer Instruments Inc Series 485) e a velocidade do ar de secagem foi medida por meio de um anemômetro de pás rotativas Airflow modelo AV6.

Ao final do processo, amostras destinadas às análises de ácido ascórbico foram acondicionadas em frascos de polietileno de $30 \mathrm{~mL}$ e armazenadas em freezer a $-18^{\circ} \mathrm{C}$. Com a intenção de se verificar o efeito da temperatura de armazenamento sobre a estabilidade do ácido ascórbico, outras duas amostras foram acondicionadas em sacos de polipropileno $(12 \times 20 \mathrm{~cm})$, selados a vácuo e armazenados por 60 dias em câmaras B.O.D. a 7 e $25^{\circ} \mathrm{C}$, visando simular a estocagem sob refrigeração e em temperatura ambiente, respectivamente. A Figura 1 resume as etapas de desidratação de goiabas por processo combinado de imersão-impregnação e secagem por convecção.

\subsection{Métodos}

Para determinação da massa inicial, os frutos foram pesados em balança de precisão Sartorius modelo BP 4100S, e as medidas de diâmetro equatorial, longitudinal e espessura da polpa dos frutos foram feitas com paquímetro. Para a determinação do estádio de maturação dos frutos, a cor da casca e a cor da polpa foram analisadas com colorímetro Minolta modelo CR 300, em três pontos distintos da amostra e a média dos resultados foram expressos em ${ }^{\circ} \mathrm{h}$ (tonalidade) e em C (cromaticidade), respectivamente.

As análises físico-químicas foram feitas em duplicata, utilizando-se reagentes com grau de pureza P.A. Foram descartadas as extremidades dos pedaços e as amostras foram homogeneizadas com microtriturador de aço inox (Tecnal modelo Turratec TE 102) e pesadas em balança analítica. O teor de água, em todas as amostras, foi determinado por gravimetria em estufa com circulação forçada de ar a $60^{\circ} \mathrm{C}$ até massa constante.

Para o preparo da solução mineral, a matéria orgânica das amostras foi oxidada via seca com incineração em mufla Quimis em temperatura $\leq 525^{\circ} \mathrm{C}$, durante aproximadamente 4 horas (até se obter cinza clara), segundo método da AOAC (1990). As cinzas obtidas foram dissolvidas em solução de $\mathrm{HCl}$ a $50 \%$ e levadas para banho de areia a $180^{\circ} \mathrm{C}$ até completa evaporação do ácido. A operação foi repetida e depois do resfriamento do cadinho, o conteúdo foi dissolvido novamente em água desionizada até completar o volume de $20 \mathrm{~mL}$. Os teores de sódio e potássio foram analisados em fotômetro de chama Analyser modelo $910 \mathrm{M}$, enquanto os teores de cálcio, ferro, magnésio, zinco e cobre foram quantificados em espectrofotômetro de absorção atômica Zeiss modelo AA-S4. Todo o material utilizado nas análises de minerais foi higienizado com detergente neutro, enxaguado em água corrente, imerso em solução ácida de áci- 


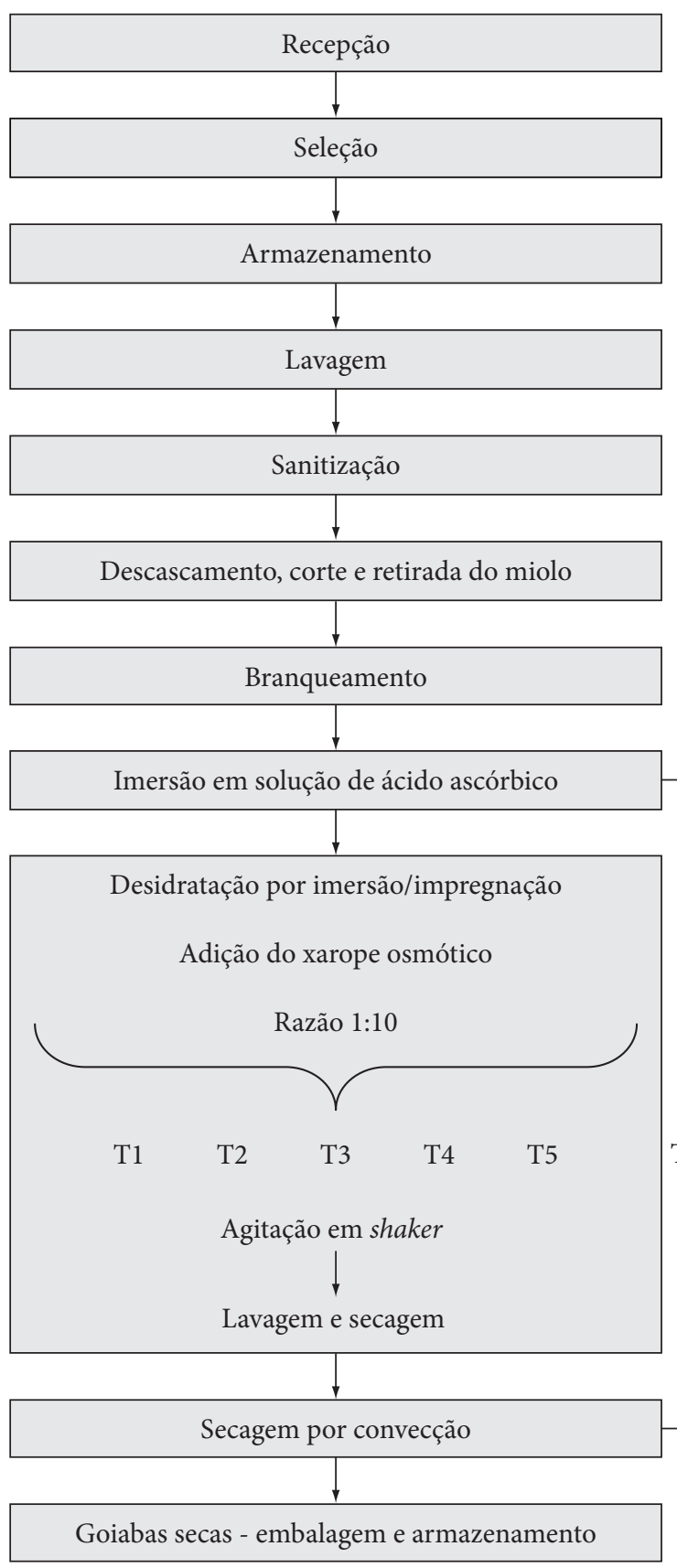

Laboratório

Cor da casca, massa, diâmetro longitudinal e equatorial

B.O.D. a $7^{\circ} \mathrm{C}$ - até cor verde-amarelada da casca ( $\mathrm{h}^{\circ}$ entre 109 e 112)

Detergente neutro/15 minutos

Água clorada a 100 ppm/15 minutos

Início da retirada das amostras

Vapor/1 minuto

$1 \% / 5$ minutos

$$
\begin{aligned}
\mathrm{T} 1 & =\text { Sacarose } 0,5 \mathrm{~g} \cdot \mathrm{mL}^{-1} \\
\mathrm{~T} 2 & =\text { Sacarose } 0,4 \mathrm{~g} \cdot \mathrm{mL}^{-1} \\
\mathrm{~T} 3 & =\text { Sacarose } 0,3 \mathrm{~g} \cdot \mathrm{mL}^{-1}+\text { sucralose } 0,2 \mathrm{~g} \cdot \mathrm{L}^{-1} \\
\mathrm{~T} 4 & =\text { Açúcar invertido } 41 \% \\
\mathrm{~T} 5 & =\text { Açúcar invertido sem diluição } \\
\mathrm{T} 6 & =\text { Controle (sem DII) }
\end{aligned}
$$

T6 Temperatura de $50^{\circ} \mathrm{C}$

Agitação de $60 \mathrm{~min}^{-1}$

Água destilada ou desionizada

Temperatura: $60^{\circ} \mathrm{C}$

Fluxo de ar: $1,25 \mathrm{~m} / \mathrm{s}$

Sacos de polipropileno em B.O.D. a 7 e $25^{\circ} \mathrm{C}$

Potes de polietileno em freezer a $-18^{\circ} \mathrm{C}$

Figura 1. Fluxograma do processo de obtenção de goiabas desidratadas pela combinação dos métodos de desidratação por imersão-impregnação e secagem por convecção.

do clorídrico $(\mathrm{pH}<1)$ por 1 hora e enxaguado três vezes com água desionizada de modo a evitar contaminação por traços de minerais. Os teores de ácido ascórbico foram determinados por titulação com solução de iodato de potássio $0,1 \mathrm{~N}$ até coloração azul, segundo as Normas Analíticas do Instituto Adolfo Lutz (PREGNOLATTO; PREGNOLATTO, 1985).

Sendo assim, a análise dos teores de minerais, para as três concentrações de sacarose e as duas de açúcar invertido, foi feita nas seguintes etapas do processamento: goiabas in natura (IN), depois da imersão em ácido ascórbico (IAA) e da desidratação por imersão-impregnação (DII). No entanto, a análise de vi- tamina C, para os cinco tratamentos em soluções osmóticas e para o tratamento controle, sem DII, foi feita para seis etapas do processamento, ou seja, goiabas in natura (IN), depois do branqueamento (BR), desidratação por imersão-impregnação (DII), secagem por convecção (SC) e 60 dias de armazenamento a 7 e $25^{\circ} \mathrm{C}$.

\subsection{Análises estatísticas}

O experimento foi realizado de acordo com o delineamento experimental em blocos casualizados (DBC), em arranjo fatorial (5 tratamentos de desidratação $\times 6$ etapas de amostragem), mais 
um tratamento adicional (controle, o T6), com três repetições, sendo cada fruto correspondente a um bloco. Os dados obtidos foram submetidos à análise de variância (ANOVA), depois da verificação da normalidade dos dados e homogeneidade das variâncias dos tratamentos pelos testes de Liliefors e Barttlet, respectivamente. As interações significativas pelo teste $F$ da ANOVA foram desdobradas e as médias dos tratamentos dentro de cada etapa ou período de amostragem foram comparadas pelo teste de Tukey a 5\% de probabilidade. Os tratamentos foram também avaliados por meio de contrastes ortogonais, por constituírem grupos de tratamentos, sendo as comparações feitas entre e dentro dos grupos, para melhor interpretação dos resultados e sua significância testada pelo teste $T$ a 1 e $5 \%$ de probabilidade. As análises estatísticas foram realizadas com o auxílio do aplicativo computacional SAEG, versão 9.0, da FUNARBE - Fundação Artur Bernardes, da Universidade Federal de Viçosa - UFV.

\section{Resultados e discussão}

\subsection{Caracterização físico-química da fruta in natura}

A caracterização físico-química das goiabas frescas (in natura) no estádio três de maturação (verde-amareladas) encontra-se na Tabela 1. O teor de água verificado encontra-se entre os teores apresentados na Tabela Brasileira de Composição de Alimentos (LIMA et al., 2006) e aqueles obtidos por Pereira et al. (2003) em goiabas cv Paluma, que são de 85 e $87 \%$, respectivamente. Azzolini, Jacomino e Bron (2004), trabalhando com a mesma cultivar de goiaba no mesmo estádio de maturação, relataram valores semelhantes de massa $(170 \pm 10 \mathrm{~g})$, cor da casca $\left(h^{\circ}\right.$ entre 108-112) e cor da polpa $(C=34,57)$.

\subsection{Teores de minerais}

A Tabela 2 apresenta os teores de minerais $\left(\mathrm{mg} .100 \mathrm{~g}^{-1} \mathrm{em}\right.$ base seca) de goiabas in natura (IN), depois da imersão em ácido ascórbico (IAA), da desidratação por imersão-impregnação (DII) em solução de sacarose a $0,5 \mathrm{~g} \cdot \mathrm{mL}^{-1}$, sacarose a $0,4 \mathrm{~g} \cdot \mathrm{mL}^{-1}$, sacarose a $0,3 \mathrm{~g} \cdot \mathrm{mL}^{-1}+$ sucralose $0,2 \mathrm{~g} \cdot \mathrm{L}^{-1}$, açúcar invertido a $41 \%$ e açúcar invertido sem diluição. Os valores dos teores de $\mathrm{K}, \mathrm{Ca}, \mathrm{Mg}$ e Zn obtidos para a goiaba fresca, após conversão para b.u. (teor de água de $87 \%$ ) variaram nos seguintes intervalos, respectivamente, 279 a $284 ; 10,4$ a 15,$0 ; 8,29$ a 12,18 e 0,11 a $0,17 \mathrm{mg} \cdot 100 \mathrm{~g}^{-1}$. Esses valores são semelhantes àqueles

Tabela 1. Características físico-químicas, em base úmida, de goiabas cv Pedro Sato no estádio de maturação três.

\begin{tabular}{lc}
\hline \multicolumn{1}{c}{ Variáveis } & Valor médio \\
\hline Teor de água (\% b.u.) & $86,7 \pm 1,1$ \\
Massa (g) & $185,5 \pm 37,3$ \\
Diâmetro longitudinal - DL (cm) & $7,9 \pm 0,8$ \\
Diâmetro equatorial - DE (cm) & $6,8 \pm 1,0$ \\
Relação DL/DE & 1,2 \\
Espessura polpa (cm) & $0,83 \pm 0,17$ \\
Cor da casca - parâmetro ${ }^{\circ}$ & $106,50 \pm 3,14$ \\
Cor da polpa - parâmetro C & $33,56 \pm 3,60$ \\
\hline
\end{tabular}

apresentados por Queiroz (2004), a saber: 176 a 280; 3,9 a 10,8; 7,3 a 11,4 e 0,16 a $0,24 \mathrm{mg} \cdot 100 \mathrm{~g}^{-1}$. Os teores de $\mathrm{Mn}(0,14$ a $\left.0,20 \mathrm{mg} \cdot 100 \mathrm{~g}^{-1}\right)$ não foram analisados pelo autor supracitado, mas encontram-se próximos $\left(0,1 \mathrm{mg} .100 \mathrm{~g}^{-1}\right)$ ao valor apresentado na Tabela Brasileira de Composição de Alimentos (LIMA et al., 2006). Quanto aos teores de sódio, os valores detectados neste trabalho contrariam aqueles obtidos por Queiroz (2004) e pela referida tabela, mas foram similares $\left(22 \mathrm{mg} .100 \mathrm{~g}^{-1}\right)$ aos encontrados por Araújo et al. (1997).

Observa-se na Tabela 2, que não houve grande variabilidade nos teores de minerais das amostras in natura. Segundo Sanchez-Castillo et al. (1998) e Hardisson et al. (2001) muitos fatores podem afetar as concentrações de mineral das plantas, como: variedade, estado de maturação, tipo e condição do solo, fertilização, irrigação e clima. As goiabas analisadas, apesar de provenientes da mesma região, foram obtidas de propriedades diferentes, podendo haver variações tanto na composição do solo quanto nas doses de fertilizantes aplicadas.

Verificou-se redução significativa dos teores de todos os minerais do produto ao final da DII, em relação aos teores encontrados na fruta in natura (IN), exceto no caso do $\mathrm{Zn}$ no tratamento com sacarose a $0,5 \mathrm{~g} \cdot \mathrm{mL}^{-1}$. Na etapa de imersão em solução de ácido ascórbico (IAA) foram observadas perdas de cerca de 20,15, 18, 18, 19 e 15\% para o $\mathrm{Na}, \mathrm{K}, \mathrm{Ca}, \mathrm{Mg}$, Zn e $\mathrm{Mn}$, respectivamente, ao passo que na etapa de DII o percentual de perdas foi muito mais expressivo, na maioria dos casos. Este fato pode ser devido à solubilidade dos minerais em água, permitindo a lixiviação dos mesmos dos tecidos da fruta para a solução hipertônica.

Para normalizar as diferenças nos teores iniciais e após imersão em ácido ascórbico e tornar possível a comparação entre os diferentes tratamentos utilizados, foi realizada uma análise das perdas dos minerais em termos percentuais na etapa que vai da imersão em ácido ascórbico (IAA) até o final da desidratação por imersão-impregnação (DII). Os tratamentos foram posteriormente comparados por meio de contrastes ortogonais entre as médias e testados pelo teste T de Student.

A Figura 2 apresenta as reduções percentuais nos teores de $\mathrm{Na}$ ao final da desidratação por imersão-impregnação (DII) em solução de sacarose a $0,5 \mathrm{~g} \cdot \mathrm{mL}^{-1}$, sacarose a $0,4 \mathrm{~g} \cdot \mathrm{mL}^{-1}$, sacarose a 0,3 g.mL $\mathrm{mL}^{-1}+$ sucralose a $0,2 \mathrm{~g} \cdot \mathrm{L}^{-1}$, açúcar invertido sem diluição e diluído a $41 \%(\mathrm{p} / \mathrm{p})$. Todos os tratamentos produziram resultados estatisticamente iguais ao final da DII, com perdas percentuais de sódio entre 40 e $60 \%$.

O contraste C1 (Tabela 3 ) revelou que durante a DII a sacarose foi menos eficiente na retenção de sódio que o açúcar invertido, enquanto os contrastes C2, C3 e C4 mostraram que não houve diferença significativa entre as duas concentrações de açúcar invertido e entre as soluções de sacarose a $0,5 \mathrm{~g} \cdot \mathrm{mL}^{-1}$, sacarose a $0,4 \mathrm{~g} \cdot \mathrm{mL}^{-1}$, sacarose a $0,3 \mathrm{~g} \cdot \mathrm{mL}^{-1}+$ sucralose a $0,2 \mathrm{~g} \cdot \mathrm{L}^{-1}$, respectivamente.

O tratamento com sacarose a 0,3 g. $\mathrm{mL}^{-1}+$ sucralose a 0,2 g. $\mathrm{L}^{-1}$ foi o mais eficiente na retenção de potássio, apresentando apenas $20 \%$ de perdas, enquanto aqueles com sacarose a $0,5 \mathrm{~g} \cdot \mathrm{mL}^{-1}$, açúcar invertido a $41 \%$ e açúcar invertido sem diluição, mostraram redução de cerca de $40 \%$ deste mineral 
(Figura 3) e o tratamento com sacarose a 0,4 g.mL $\mathrm{mL}^{-1}$ apresentou valor intermediário de $30 \%$.

Ao contrário do que ocorreu com o sódio, no contraste C1 (Tabela 3) observou-se que durante a DII a sacarose proporcionou maior retenção de potássio que o açúcar invertido. No entanto, no que diz respeito às diferentes concentrações de sacarose, a diluição a $0,5 \mathrm{~g} \cdot \mathrm{mL}^{-1}$ proporcionou maiores perdas de K que aquelas a $0,4 \mathrm{~g} \cdot \mathrm{mL}^{-1}$ (C3) e a $0,3 \mathrm{~g} \cdot \mathrm{mL}^{-1}$ (C4), possivelmente por facilitar a saída de água das amostras, carreando maior quantidade de solutos da fruta para o meio. No caso do açúcar invertido, não foi verificada diferença significativa entre as duas concentrações utilizadas (C2).

Tanto para o Ca quanto para o Mg, Figuras 4 e 5, respectivamente, não foram verificadas diferenças significativas entre os tratamentos ao final da DII. Os percentuais de perdas também foram semelhantes para estes dois minerais, entre 39,8 a 47,5\% e 34,6 a $47,9 \%$, para o $\mathrm{Ca}$ e o $\mathrm{Mg}$, respectivamente. O mesmo pôde ser observado por meio dos contrastes C1, C2, C3 e C4,

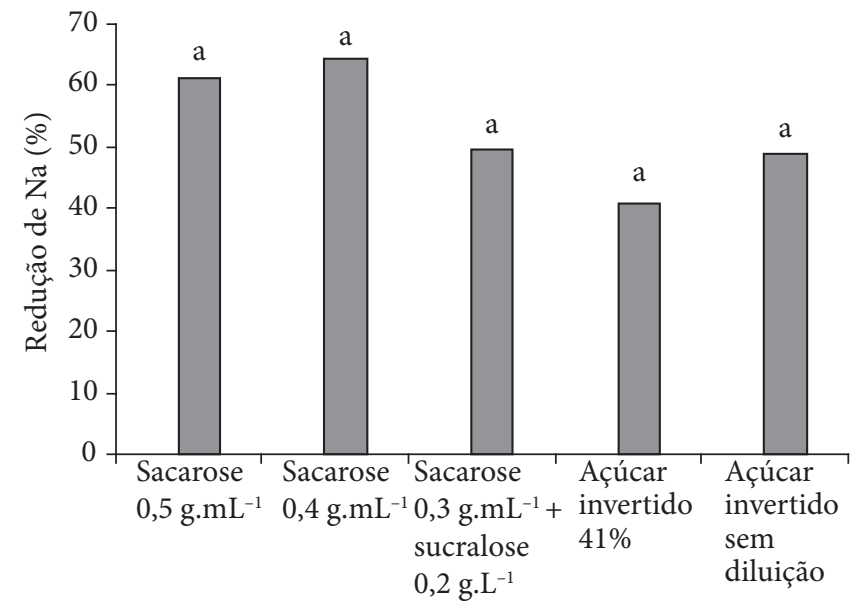

Figura 2. Redução percentual de Na em pedaços de goiaba entre a imersão em ácido ascórbico e o final da DII. Médias seguidas de mesma letra não diferem entre si, a 5\% de probabilidade, pelo teste de Tukey.

Tabela 2. Teores de $\mathrm{Na}, \mathrm{K}, \mathrm{Ca}, \mathrm{Mg}$, Zn e Mn (mg.100 g-1 em base seca) de pedaços de goiaba in natura (IN), após imersão em solução de ácido ascórbico (IAA) e após desidratação por imersão-impregnação (DII).

\begin{tabular}{|c|c|c|c|c|c|c|}
\hline \multirow[t]{3}{*}{ Mineral } & \multirow[t]{3}{*}{ Etapa } & \multicolumn{5}{|c|}{ Tratamento } \\
\hline & & \multicolumn{3}{|c|}{ Sacarose } & \multicolumn{2}{|c|}{ Açúcar invertido } \\
\hline & & $0,5 \mathrm{~g} \cdot \mathrm{mL}^{-1}$ & $0,4 \mathrm{~g} \cdot \mathrm{mL}^{-1}$ & $\begin{array}{c}0,3 \text { g.mL } \mathrm{mL}^{-1}+ \\
\text { Sucralose } 0,2 \text { g.L }\end{array}$ & $41 \%(\mathrm{p} / \mathrm{p})$ & Sem diluição \\
\hline \multirow[t]{3}{*}{$\mathrm{Na}$} & IN & $197,69^{\mathrm{aA}}$ & $183,30^{\text {aA }}$ & $223,41^{\mathrm{aA}}$ & $204,14^{\mathrm{aA}}$ & $233,14^{\mathrm{aA}}$ \\
\hline & IAA & $158,41^{\mathrm{aA}}$ & $150,44^{\mathrm{aA}}$ & $173,85^{\mathrm{aA}}$ & $170,53^{\mathrm{aA}}$ & $180,48^{\mathrm{bA}}$ \\
\hline & DII & $58,65^{\mathrm{bA}}$ & $53,27^{\mathrm{bA}}$ & $87,88^{\mathrm{bA}}$ & $99,26^{\mathrm{bA}}$ & $92,69^{\mathrm{cA}}$ \\
\hline \multirow[t]{3}{*}{$\mathrm{K}$} & IN & $2184,72^{\mathrm{aA}}$ & $2144,80^{\mathrm{aA}}$ & $2186,20^{\mathrm{aA}}$ & $2174,00^{\mathrm{aA}}$ & $2149,40^{\mathrm{aA}}$ \\
\hline & IAA & $1798,29^{\mathrm{bA}}$ & $1750,90^{\mathrm{bA}}$ & $1834,30^{\mathrm{aA}}$ & $1863,60^{\mathrm{aA}}$ & $1944,50^{\mathrm{aA}}$ \\
\hline & DII & $989,64^{\mathrm{cB}}$ & $1217,75^{\mathrm{AB}}$ & $1459,05^{\mathrm{bA}}$ & $1031,63^{\mathrm{bAB}}$ & $1205,40^{\mathrm{bAB}}$ \\
\hline \multirow[t]{3}{*}{$\mathrm{Ca}$} & IN & $80,17^{\mathrm{aB}}$ & $105,50^{\mathrm{aA}}$ & $115,29^{\mathrm{aA}}$ & $107,42^{\mathrm{aA}}$ & $97,75^{\mathrm{aAB}}$ \\
\hline & IAA & $65,45^{\mathrm{aB}}$ & $86,98^{\mathrm{aAB}}$ & $92,41^{\mathrm{bA}}$ & $85,72^{\mathrm{bAB}}$ & $83,30^{\mathrm{aAB}}$ \\
\hline & DII & $37,84^{\mathrm{bA}}$ & $46,68^{\mathrm{bA}}$ & $55,58^{\mathrm{cA}}$ & $45,10^{\mathrm{cA}}$ & $48,58^{\mathrm{bA}}$ \\
\hline \multirow[t]{3}{*}{$\mathrm{Mg}$} & IN & $63,80^{\mathrm{aB}}$ & $78,26^{\mathrm{aAB}}$ & $93,69^{\mathrm{aA}}$ & $86,10^{\mathrm{aA}}$ & $85,29^{\mathrm{aA}}$ \\
\hline & IAA & $55,21^{\mathrm{aB}}$ & $62,99^{\mathrm{aAB}}$ & $77,30^{\mathrm{aA}}$ & $70,49^{\mathrm{aAB}}$ & $67,60^{\mathrm{bAB}}$ \\
\hline & DII & $32,36^{\mathrm{bA}}$ & $40,69^{\mathrm{bA}}$ & $50,95^{\mathrm{bA}}$ & $36,08^{\mathrm{bA}}$ & $35,72^{\mathrm{cA}}$ \\
\hline \multirow[t]{3}{*}{$\mathrm{Zn}$} & IN & $0,87^{\mathrm{aB}}$ & $1,23^{\mathrm{aAB}}$ & $1,31^{\mathrm{aAB}}$ & $1,35^{\mathrm{aA}}$ & $1,16^{\mathrm{aAB}}$ \\
\hline & IAA & $0,76^{\mathrm{aA}}$ & $0,99^{\mathrm{aA}}$ & $1,04^{\mathrm{abA}}$ & $1,04^{\mathrm{aA}}$ & $0,94^{\mathrm{aA}}$ \\
\hline & DII & $0,56^{\mathrm{aA}}$ & $0,51^{\mathrm{bA}}$ & $0,70^{\mathrm{bA}}$ & $0,56^{\mathrm{bA}}$ & $0,53^{\mathrm{bA}}$ \\
\hline \multirow[t]{3}{*}{$\mathrm{Mn}$} & IN & $1,33^{\mathrm{aA}}$ & $1,40^{\mathrm{aA}}$ & $1,58^{\mathrm{aA}}$ & $1,12^{\mathrm{aA}}$ & $1,07^{\mathrm{aA}}$ \\
\hline & IAA & $1,18^{\mathrm{abA}}$ & $1,12^{\mathrm{abA}}$ & $1,33^{\mathrm{abA}}$ & $1,00^{\mathrm{aA}}$ & $0,87^{\mathrm{abA}}$ \\
\hline & DII & $0,69^{\mathrm{bA}}$ & $0,66^{\mathrm{bA}}$ & $0,97^{\mathrm{bA}}$ & $0,44^{\mathrm{bA}}$ & $0,47^{\mathrm{bA}}$ \\
\hline
\end{tabular}

Para cada mineral valores seguidos de mesma letra minúscula na coluna ou maiúscula na linha não diferem entre si, a 5\% de probabilidade, pelo teste de Tukey.

Tabela 3. Contrastes das perdas percentuais de minerais entre as médias dos tratamentos sacarose a $0,5 \mathrm{~g} \cdot \mathrm{mL}^{-1}\left(\mathrm{~m}_{1}\right)$, sacarose a $0,4 \mathrm{~g} \cdot \mathrm{mL}^{-1}\left(\mathrm{~m}_{2}\right)$, sacarose a $0,3 \mathrm{~g} \cdot \mathrm{mL}^{-1}+$ sucralose a $0,2 \mathrm{~g} \cdot \mathrm{L}^{-1}\left(\mathrm{~m}_{3}\right)$, açúcar invertido a $41 \%\left(\mathrm{~m}_{4}\right)$ e açúcar invertido sem diluição $\left(\mathrm{m}_{5}\right)$, em pedaços de goiaba ao final da DII.

\begin{tabular}{|c|c|c|c|c|c|c|}
\hline \multirow[t]{2}{*}{ Contraste } & \multicolumn{6}{|c|}{ Valor do contraste } \\
\hline & $\mathrm{Na}$ & $\mathrm{K}$ & $\mathrm{Ca}$ & $\mathrm{Mg}$ & $\mathrm{Zn}$ & $\mathrm{Mn}$ \\
\hline C1 $y=2\left(m_{1}+m_{2}+m_{3}\right)-3\left(m_{4}+m_{5}\right)$ & $81,38^{\star *}$ & $-51,51^{\star *}$ & $-11,15^{\mathrm{ns}}$ & $-62,89^{* *}$ & $-67,49^{* *}$ & $-84,95^{\star *}$ \\
\hline $\mathrm{C} 2 \quad \mathrm{y}=\mathrm{m}_{5}-\mathrm{m}_{4}$ & $7,86^{\mathrm{ns}}$ & $-4,41^{\mathrm{ns}}$ & $-5,25^{\mathrm{ns}}$ & $0,19^{\text {ns }}$ & $-1,21^{\mathrm{ns}}$ & $-8,83^{\mathrm{ns}}$ \\
\hline C3 $y=m_{1}-m_{2}$ & $-3,28^{\text {ns }}$ & $14,93^{\star *}$ & $-3,67^{\mathrm{ns}}$ & $6,53^{\text {ns }}$ & $-21,32^{\star *}$ & $2,33^{\text {ns }}$ \\
\hline C4 $y=m_{1}-m_{3}$ & $11,55^{\mathrm{ns}}$ & $24,82^{\star *}$ & $2,99^{\text {ns }}$ & $7,38^{\text {ns }}$ & $-6,72^{\mathrm{ns}}$ & $16,49^{*}$ \\
\hline
\end{tabular}

${ }^{\star} \mathrm{e}^{\star *}$ : significativos a 5 e $1 \%$ de probabilidade, respectivamente, pelo teste $t$; e ns: não significativo. 


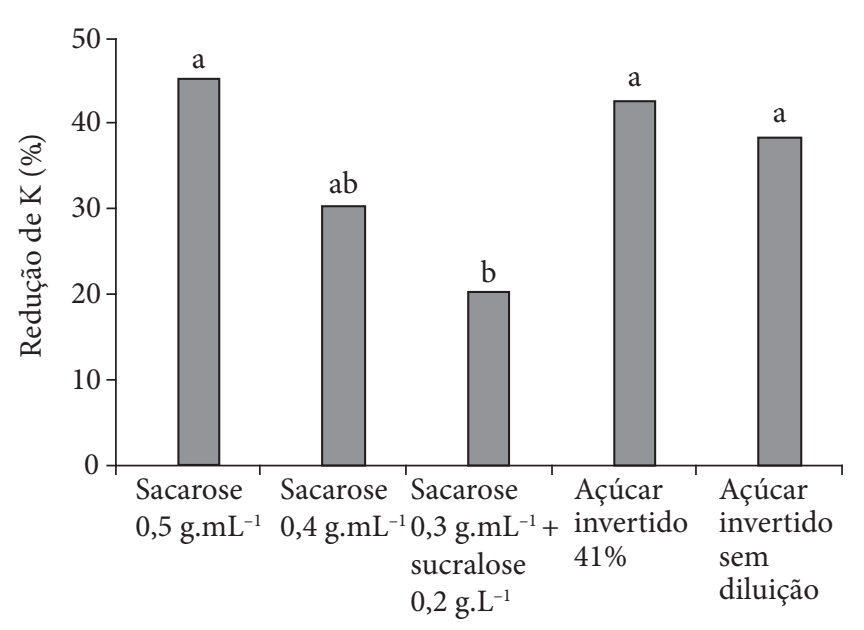

Figura 3. Redução percentual de K em pedaços de goiaba entre a imersão em ácido ascórbico e o final da DII. Médias seguidas de mesma letra não diferem entre si, a 5\% de probabilidade, pelo teste de Tukey.

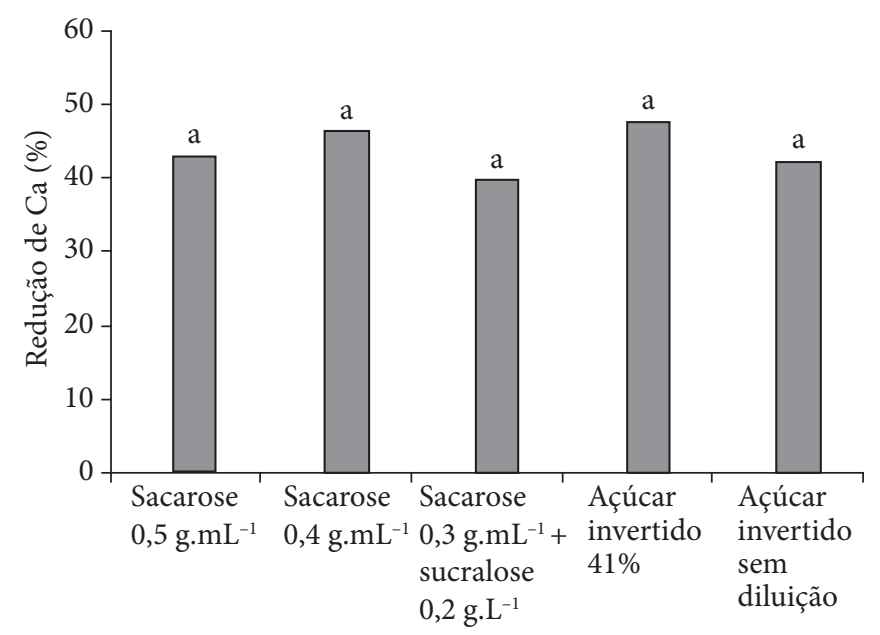

Figura 4. Redução percentual de Ca em pedaços de goiaba entre a imersão em ácido ascórbico e o final da DII. Médias seguidas de mesma letra não diferem entre si, a $5 \%$ de probabilidade, pelo teste de Tukey.

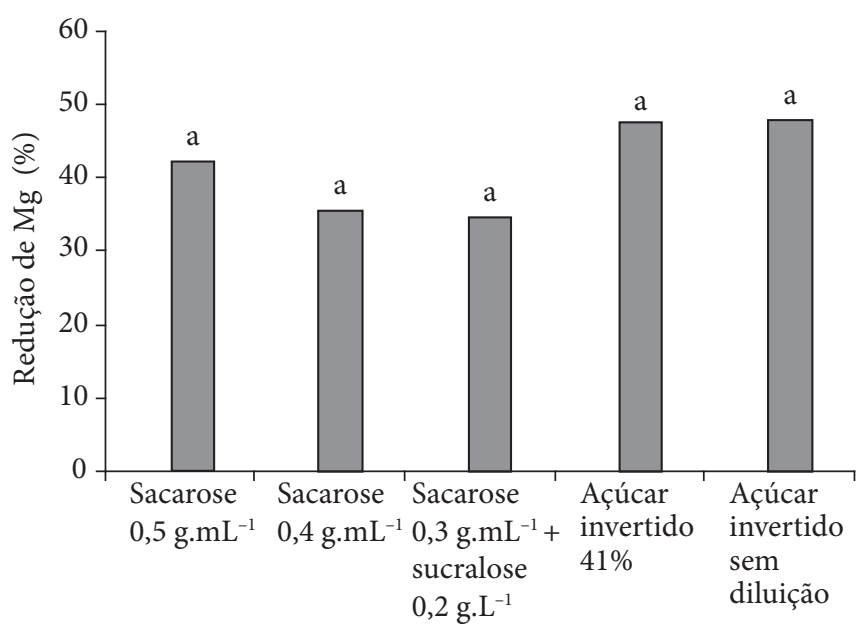

Figura 5. Redução percentual de $\mathrm{Mg}$ em pedaços de goiaba entre a imersão em ácido ascórbico e o final da DII. Médias seguidas de mesma letra não diferem entre si, a $5 \%$ de probabilidade, pelo teste de Tukey. para o caso do cálcio, e C2, C3 e C4, para o caso do Mg, em que todas as médias dos tratamentos contrastados foram consideradas estatisticamente iguais (Tabela 3). Entretanto, o C1 revelou que a sacarose proporcionou maior percentual de retenção de Mg que o açúcar invertido.

No caso do zinco (Figura 6), durante a DII, os maiores fluxos deste mineral para a solução osmótica ocorreram nos tratamentos com sacarose a 0,4 g. $\mathrm{mL}^{-1}$, açúcar invertido a $41 \%$ e açúcar invertido sem diluição (47\% em média), o menor fluxo foi verificado nos procedimentos com sacarose a $0,5 \mathrm{~g} \cdot \mathrm{mL}^{-1}$ (26\%). A solução de sacarose a $0,3 \mathrm{~g} \cdot \mathrm{mL}^{-1}+$ sucralose a $0,2 \mathrm{~g} \cdot \mathrm{L}^{-1}$ levou a perdas intermediárias (33\%). Conforme mostrou o contraste C1 (Tabela 3), o açúcar invertido proporcionou menor retenção de $\mathrm{Zn}$ que a sacarose, semelhante ao que ocorreu com os minerais $\mathrm{Mg}$ e $\mathrm{K}$. No entanto, de acordo com o C4, houve diferença significativa entre as concentrações de sacarose a 0,5 e 0,4 g.mL $\mathrm{m}^{-1}$, em que a menor concentração provocou maior perda deste mineral.

Semelhante ao ocorrido com o potássio, os tratamentos contendo açúcar invertido diluído a $41 \%$ e sem diluição e os com sacarose a 0,5 e $0,4 \mathrm{~g} \cdot \mathrm{mL}^{-1}$ foram os que proporcionaram maior redução de Mn na DII, com valores de 54,8; 46,0; 42,5 e 40,2\%, respectivamente (Figura 7). A solução de sacarose a $0,3 \mathrm{~g} \cdot \mathrm{mL}^{-1}+$ sucralose a 0,2 g.L. $\mathrm{L}^{-1}$ levou à menor perda deste mineral $(26,1 \%)$. Mais uma vez, o contraste $\mathrm{C} 1$ revelou que a sacarose foi capaz de manter os teores de manganês em níveis mais elevados no final da DII que o açúcar invertido, assim como no caso do K, $\mathrm{Mg}$ e $\mathrm{Zn}$ (Tabela 3). Por meio do C4, verificou-se que as concentrações de sacarose a 0,5 e a $0,3 \mathrm{~g} \cdot \mathrm{mL}^{-1}$ proporcionaram perdas significativamente diferentes nas amostras de goiaba. A solução mais concentrada, possivelmente, acarretou maior lixiviação deste mineral, de forma análoga ao que foi notado com o K.

Verifica-se, portanto, que durante a DII, o açúcar invertido, tanto sem diluição quanto diluído a $41 \%$ foi menos eficiente na manutenção dos níveis dos minerais analisados, com exceção do K. Isto pode ser devido ao maior percentual de desidratação causado por este tipo de açúcar na DII, levando à maior lixiviação

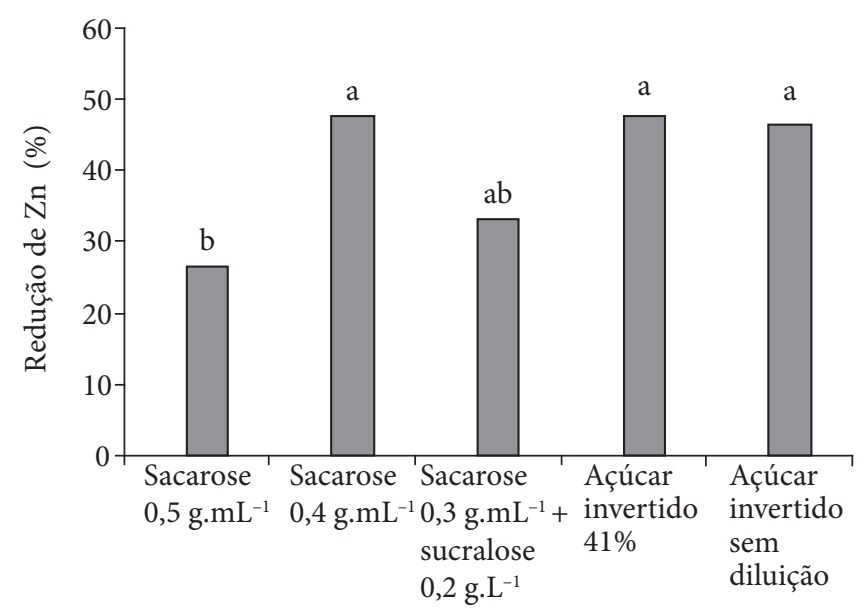

Figura 6. Redução percentual de Zn em pedaços de goiaba entre a imersão em ácido ascórbico e o final da DII. Médias seguidas de mesma letra não diferem entre si, a $5 \%$ de probabilidade, pelo teste de Tukey. 
dos mesmos para a solução osmótica. Quanto às concentrações de sacarose, a diluição a $0,5 \mathrm{~g} \cdot \mathrm{mL}^{-1}$ provocou maior redução nos teores de $\mathrm{K}$ e $\mathrm{Mg}$ que a 0,3 g. $\mathrm{mL}^{-1}$ e maior redução no teor de $\mathrm{K}$ e menor de $\mathrm{Zn}$ que a diluição a $0,4 \mathrm{~g} \cdot \mathrm{mL}^{-1}$. Nota-se, assim, que os minerais estudados apresentaram comportamentos distintos face aos diferentes solutos e às concentrações das soluções osmóticas empregados no processo de desidratação por imersãoimpregnação, porém, em todos os casos há redução significativa dos teores destes elementos durante o processo.

Os resultados obtidos para as perdas percentuais dos minerais $\mathrm{Na}(40,9$ a 64,4\%), K (20,4 a 45,2\%), Ca (39,8 a 47,5\%) e $\mathrm{Mg}(34,6$ a 47,9\%) encontram-se dentro da faixa de valores apresentados por Peiró et al. (2006) e por Peiró-Mena et al. (2006) depois do processo de desidratação osmótica de grapefruit e de abacaxi, respectivamente, em solução reciclada de sacarose a $55^{\circ}$ Brix por 3 horas a $30{ }^{\circ} \mathrm{C}$. Para grapefruit, as perdas apresentadas foram de 23 a $51 \%$ de Na, 48 a $68 \%$ de K, 23 a $68 \%$ de Ca e 19 a 35\% de Mg. Entretanto, os percentuais de redução nas amostras de abacaxi foram ainda maiores que nas amostras de grapefruit. No caso do sódio variaram de 53 a 70\% e no do cálcio, de 28 a $82 \%$. As reduções foram semelhantes no caso do potássio, 23 a $60 \%$, e no do magnésio, 11 a $42 \%$. Estes autores analisaram ainda os teores de minerais das soluções osmóticas

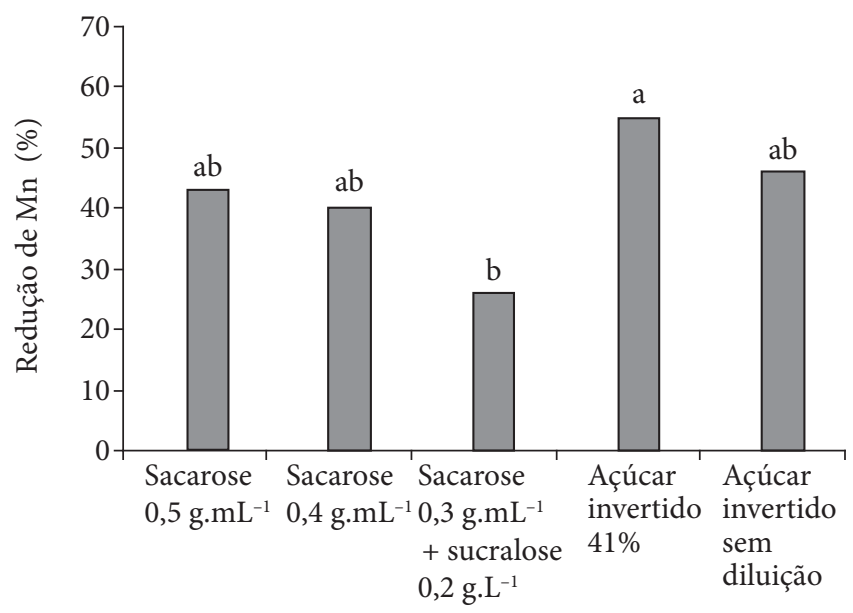

Figura 7. Redução percentual de Mn em pedaços de goiaba entre a imersão em ácido ascórbico e o final da DII. Médias seguidas de mesma letra não diferem entre si, a $5 \%$ de probabilidade, pelo teste de Tukey. e observaram que os mesmos eram recuperados nos xaropes utilizados na desidratação, comprovando assim a ocorrência do fluxo destes nutrientes da fruta para o meio hipertônico. Notase que as variações dos resultados nos trabalhos supracitados foram ainda maiores que as verificadas no presente trabalho. Tanto Rodriguez quanto Bognar, citados por Krešić, Lelas e Šimundić (2004), também descreveram perdas de minerais entre 25 a $50 \%$ no processo de cristalização de frutas. Para o $\mathrm{Zn}$ e o Mn não foram encontrados na literatura relatos quanto ao grau de perdas provocadas pela DII.

\subsection{Teor de vitamina C}

Os teores de vitamina $\mathrm{C}$ das amostras de goiaba in natura $\mathrm{e}$ após branqueamento (BR), desidratação por imersão-impregnação (DII), secagem por convecção (SC) e 60 dias de armazenamento sob refrigeração a 7 e $25^{\circ} \mathrm{C}$ são apresentados na Tabela 4. A concentração média de ácido ascórbico das amostras frescas, depois de correção para b.u., foi de 49,1 mg. $100 \mathrm{~g}^{-1}$ de polpa, estando de acordo com o valor observado por Azzolini, Jacomino e Bron (2004) que, ao trabalhar com frutos da variedade Pedro Sato, encontraram teor médio de 48,8 mg. $100 \mathrm{~g}^{-1} \mathrm{de}$ polpa.

Verificou-se redução dos teores de vitamina C durante o processamento e armazenamento em todos os tratamentos. No branqueamento percebeu-se diminuição desta vitamina, porém, não significativa. Dermesonlouoglou e Giannakourou (2007) relataram perdas de $26 \%$ de ácido ascórbico no branqueamento de tomates por imersão em água a $80{ }^{\circ} \mathrm{C}$ por 80 segundos. A etapa de DII, no presente trabalho, foi capaz de reter grande parte do ácido ascórbico da fruta, confirmando os dados de Erle e Schubert (2001), que mostraram retenção de $100 \%$ de vitamina $\mathrm{C}$ em maçãs e perdas não superiores a $10 \%$ em morangos desidratados em solução de sacarose a $60 \%$ por 25 horas. Nesta etapa (DII), as perdas foram estatisticamente significativas apenas no tratamento contendo açúcar invertido sem diluição. Ao contrário, na etapa seguinte (SC), houve redução significativa dos níveis desta vitamina em praticamente todos os tratamentos, exceto no caso do açúcar invertido a $41 \%$. Os resultados da análise de variância revelaram que o armazenamento a $7{ }^{\circ} \mathrm{C}$ proporcionou maior retenção de vitamina $\mathrm{C}$ que o armazenamento a $25^{\circ} \mathrm{C}$ nos tratamentos com sacarose a $0,5 \mathrm{~g} \cdot \mathrm{mL}^{-1}$, sacarose a $0,4 \mathrm{~g} \cdot \mathrm{mL}^{-1}$ e açúcar invertido a $41 \%$, confirmando que a temperatura exerce grande influência na degradação do ácido ascórbico, conforme descrevem Vikram,

Tabela 4. Teor de vitamina C em goiaba in natura (IN), depois do branqueamento (BR), desidratação por imersão-impregnação (DII), secagem por convecção (SC) e 60 dias de armazenamento a 7 e $25^{\circ} \mathrm{C}$.

\begin{tabular}{|c|c|c|c|c|c|c|}
\hline \multirow[t]{3}{*}{ Etapa } & \multicolumn{6}{|c|}{ Tratamento } \\
\hline & \multicolumn{3}{|c|}{ Sacarose } & \multicolumn{2}{|c|}{ Açúcar invertido } & \multirow[t]{2}{*}{ Controle (sem DII) } \\
\hline & 0,5 g.mL $\mathrm{mL}^{-1}$ & 0,4 g.mL $\mathrm{mL}^{-1}$ & $\begin{array}{c}0,3 \mathrm{~g} \mathrm{~mL}^{-1}+ \\
\text { sucralose } 0,2 \text { g. } \mathrm{L}^{-1}\end{array}$ & $41 \%(\mathrm{p} / \mathrm{p})$ & Sem diluição & \\
\hline $\mathrm{BR}$ & $287,34^{\mathrm{aC}}$ & $389,14^{\mathrm{aB}}$ & $388,57^{\mathrm{abB}}$ & $266,35^{\mathrm{aC}}$ & $472,50^{\mathrm{aAB}}$ & $528,50^{\mathrm{aA}}$ \\
\hline DII & $274,25^{\mathrm{aAB}}$ & $324,02^{\mathrm{aA}}$ & $326,33^{\mathrm{bA}}$ & $240,34^{\mathrm{abB}}$ & $334,64^{\mathrm{bA}}$ & - \\
\hline $25^{\circ} \mathrm{C}$ & $74,18^{\mathrm{cA}}$ & $85,81^{\mathrm{cA}}$ & $87,26^{\mathrm{cA}}$ & $64,74^{\mathrm{dA}}$ & $63,86^{\mathrm{cA}}$ & $88,31^{\mathrm{bA}}$ \\
\hline
\end{tabular}

Valores seguidos de mesma letra minúscula na coluna ou maiúscula na linha não diferem entre si, a 5\% de probabilidade, pelo teste de Tukey. 
Ramesh e Prapulla (2005). Marcy, Hansen e Graumilch (1989) observaram perda da ordem de $40 \%$ nos teores desta vitamina depois de seis meses de armazenamento a 4 e $6{ }^{\circ} \mathrm{C}$ em bebidas à base de laranja embaladas assepticamente. Quando estocadas a 22 ou $30^{\circ} \mathrm{C}$, a perda foi superior a $75 \%$. Nos tratamentos com sacarose a 0,3 g.mL $\mathrm{mL}^{-1}$ + sucralose a $0,2 \mathrm{~g} \cdot \mathrm{L}^{-1}$, açúcar invertido sem diluição e controle (sem DII), não houve diferença significativa entre as três últimas etapas do processo.

As variações nos teores de vitamina $\mathrm{C}$ in natura (Tabela 4) devem-se, possivelmente, às variações nos níveis de nutrientes no solo e adubação, no estádio de maturação dos frutos e na localização dos mesmos na goiabeira, levando a diferenças na incidência de luz solar. Frutos mais expostos ao sol apresentam maior concentração desta vitamina, e a adubação rica em potássio e manganês aumenta os teores de ácido ascórbico nos frutos, enquanto que a adubação de nitrogênio e boro os diminuem (HOBSON; DAVIES, 1971). Com a finalidade de normalizar esta grande variação, os tratamentos foram comparados entre si pelos percentuais de redução no teor desta vitamina em cada etapa e não pelos teores de vitamina $\mathrm{C}$ das amostras. A Figura 8 apresenta, a partir do branqueamento, as perdas percentuais acumuladas de vitamina $\mathrm{C}$ depois da DII e secagem por convecção e ao final do armazenamento por 60 dias a 7 e $25^{\circ} \mathrm{C}$. Os valores foram comparados depois do branqueamento, uma vez que os tratamentos só foram aplicados depois desta etapa.

Constatou-se que a DII com açúcar invertido sem diluição proporcionou menor retenção de vitamina C ( $29 \%$ de perdas) que as soluções de sacarose ( $4,6 \%$ de perdas) e açúcar invertido a $41 \%$ (9,4\% de perdas). Esse fato pode ser devido à formação de uma camada de sacarose na superfície das amostras, evitando assim a entrada de $\mathrm{O}_{2}$ para o interior das células e a conseqüente oxidação do ácido ascórbico a ácido 2,3 dioxi L-gulônico, conforme argumentam Torreggiani e Bertolo (2001). Quanto ao açúcar invertido, o tratamento com diluição possivelmente provocou menor potencial osmótico que aquele realizado sem diluição, provocando menor fluxo de água e de solutos hidrossolúveis como a vitamina $\mathrm{C}$, do interior das amostras para o meio. Os tratamentos sacarose a 0,4 g.mL $\mathrm{mL}^{-1}$ e sacarose a $0,3 \mathrm{~g} \cdot \mathrm{mL}^{-1}+$ sucralose a $0,2 \mathrm{~g} . \mathrm{L}^{-1}$ apresentaram percentuais de perdas intermediários (16\%) em relação aos anteriores (Figura 8). Peiró et al. (2006), em estudo de reciclagem da solução de sacarose a $55^{\circ}$ Brix na desidratação osmótica de grapefruit, observaram perdas de ácido ascórbico entre 6 e 12\%, valores semelhantes aos encontrados neste trabalho.

$\mathrm{O}$ contraste $\mathrm{C} 1$ entre as médias dos tratamentos (Tabela 5) mostrou não haver diferença significativa entre os solutos sacarose e açúcar invertido na DII. Por outro lado, o C3 revelou que o açúcar invertido sem diluição provoca maior perda de vitamina C que o diluído a $41 \%$, conforme já discutido no parágrafo anterior. Chandrasekaran e King citados por Bolin et al. (1983), comparando as características de difusão da sacarose e da frutose, determinaram que a frutose apresenta coeficiente de difusão 32\% maior que o da sacarose. Para os diferentes níveis de diluição das soluções de sacarose, o C4 mostrou que a sacarose diluída a $0,5 \mathrm{~g} \cdot \mathrm{mL}^{-1}$ induz a maior preservação da vitamina $\mathrm{C}$ que a diluição a 0,4 g.mL $\mathrm{mL}^{-1}$, o mesmo não ocorrendo em relação à diluição $\mathrm{a} 0,3 \mathrm{~g} \cdot \mathrm{mL}^{-1}(\mathrm{C} 5)$.

Ficou evidenciado que a secagem por convecção (SC) levou a perdas significativas de vitamina $\mathrm{C}$, entre 32 a $68 \%$, em todos os tratamentos aplicados (Figura 8). No entanto, estes valores

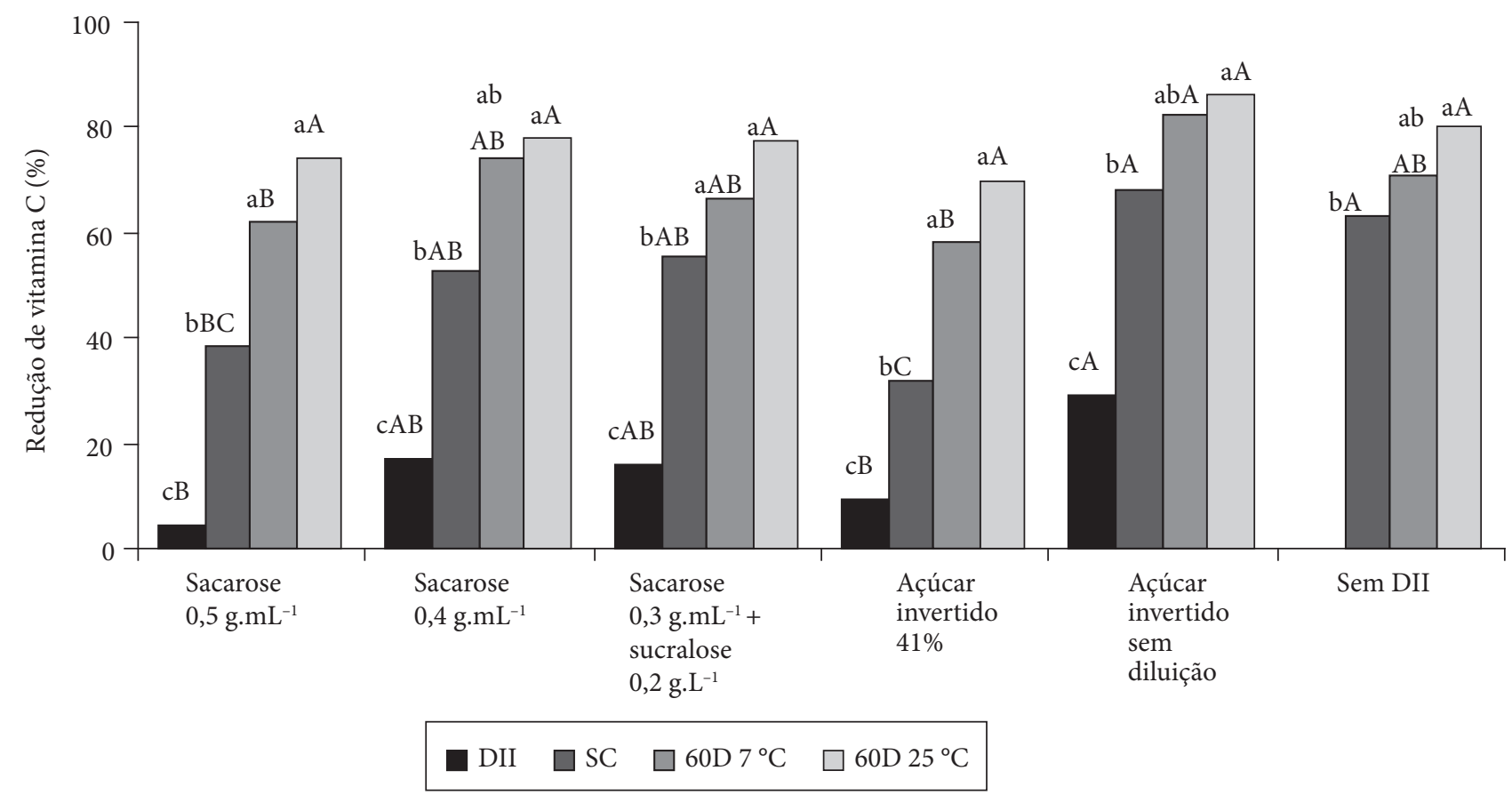

Figura 8. Redução de vitamina C (\%) em pedaços de goiaba a partir do branqueamento, depois da desidratação por imersão-impregnação (DII), secagem por convecção (SC) e 60 dias de armazenamento a 7 e $25^{\circ} \mathrm{C}$. Letras diferentes indicam diferença significativa (p $\left.<0,05\right)$ entre as médias dos tratamentos na mesma etapa (letras maiúsculas) e entre diferentes etapas para o mesmo tratamento (letras minúsculas). 
Tabela 5. Contrastes entre as médias das perdas percentuais de vitamina $\mathrm{C}$ em goiaba nos tratamentos com DII: sacarose a 0,5 g.mL $\mathrm{L}^{-1}\left(\mathrm{~m}_{1}\right)$, sacarose a 0,4 g.mL $\mathrm{mL}^{-1}\left(\mathrm{~m}_{2}\right)$, sacarose a 0,3 g. $\mathrm{mL}^{-1}+$ sucralose a 0,2 g. $\mathrm{L}^{-1}\left(\mathrm{~m}_{3}\right)$, açúcar invertido a $41 \%\left(\mathrm{~m}_{4}\right)$, açúcar invertido sem diluição $\left(\mathrm{m}_{5}\right)$ e grupo controle (sem DII) $\left(\mathrm{m}_{6}\right)$.

\begin{tabular}{|c|c|c|c|c|c|}
\hline \multicolumn{2}{|r|}{ Contraste } & \multicolumn{4}{|c|}{ Valor do contraste (perdas de vitamina C) } \\
\hline & & DII & SC & 60 dias a $7{ }^{\circ} \mathrm{C}$ & 60 dias a $25^{\circ} \mathrm{C}$ \\
\hline $\mathrm{C} 1$ & $y=5 m_{6}-\left(m_{1}+m_{2}+m_{3}+m_{4}+m_{5}\right)$ & - & $69,5928^{* *}$ & $10,5404^{\mathrm{ns}}$ & $16,2459 \mathrm{~ns}$ \\
\hline $\mathrm{C} 2$ & $\mathrm{y}=2\left(\mathrm{~m}_{1}+\mathrm{m}_{2}+\mathrm{m}_{3}\right)-3\left(\mathrm{~m}_{4}+\mathrm{m}_{5}\right)$ & $-40,6344^{\mathrm{ns}}$ & $-6,8846^{\mathrm{ns}}$ & $-16,8853^{\text {ns }}$ & $-10,3408^{\mathrm{ns}}$ \\
\hline $\mathrm{C} 3$ & $\mathrm{y}=\mathrm{m}_{5}-\mathrm{m}_{4}$ & $19,8684^{* *}$ & $36,2918^{\star *}$ & $24,5509^{* *}$ & $16,5182^{\star *}$ \\
\hline $\mathrm{C} 4$ & $\mathrm{y}=\mathrm{m}_{1}-\mathrm{m}_{2}$ & $-12,2102^{\star}$ & $-14,3729^{\star}$ & $-12,3265^{\star}$ & $-3,8529^{\text {ns }}$ \\
\hline $\mathrm{C} 5$ & $\mathrm{y}=\mathrm{m}_{1}-\mathrm{m}_{3}$ & $-11,5798^{\mathrm{ns}}$ & $-16,7367^{\star *}$ & $-4,5117^{\mathrm{ns}}$ & $-3,0817^{\mathrm{ns}}$ \\
\hline
\end{tabular}

* $\mathrm{e}^{* *}$ : significativos a 5 e $1 \%$ de probabilidade, respectivamente, pelo teste $T$; ns: não significativo.

foram menores que os apresentados por Forni et al. (1997), que mostraram redução de cerca de 98, 90 e 99\% nos teores de ácido ascórbico, em amostras de damascos desidratados por 45 minutos em soluções de $65 \%$ de sacarose, maltose e sorbitol, respectivamente, após a secagem em secador com circulação de ar a $65^{\circ} \mathrm{C}$. Segundo Khraisheh, McMinn e Magee (2004), a estabilidade e retenção da vitamina $\mathrm{C}$ não são dependentes apenas das condições de secagem, mas também do teor de água das amostras. A umidade pode afetar a diluição do ácido ascórbico e dos reagentes na fase aquosa, ou seja, ao mesmo tempo em que o teor de água diminui, o grau de diluição reduz e as taxas de reação aumentam, ocasionando a mais baixa retenção de ácido ascórbico. Num estágio mais tardio da secagem, a temperatura interna da amostra é também mais elevada em comparação àquela dos estágios iniciais, e a expansão da matriz pode expor novos sítios catalíticos, contribuindo assim com o decréscimo dos teores de vitamina C. Além disso, as amostras, durante a secagem por convecção, são expostas por mais tempo a outros fatores que também contribuem para a degradação do ácido ascórbico como luz e $\mathrm{O}_{2}$, o que poderia justificar as maiores perdas desta vitamina durante esta etapa.

O C1 (Tabela 5) revelou que as amostras não tratadas osmoticamente proporcionaram menor retenção de ácido ascórbico na etapa de secagem que aquelas submetidas a qualquer um dos tratamentos osmóticos utilizados. Este fato confirmou relatos da literatura que afirmam que uma etapa osmótica anterior à secagem convencional contribui para melhorar a estabilidade do ácido ascórbico. Isto se deve ao menor colapso estrutural que ocorre nos frutos pré-tratados em relação aos não prétratados osmoticamente na etapa subseqüente de secagem (TORREGGIANI; BERTOLO, 2001). Da mesma forma, Riva et al. (2005) demonstraram que o ácido ascórbico foi melhor retido em cubos de damasco osmodesidratados em solução de sacarose e sorbitol a $60 \%$, principalmente em sorbitol, do que naqueles não tratados por osmose, depois da secagem em secador com circulação de ar.

Ainda na etapa de secagem por convecção, as amostras pré-desidratadas em açúcar invertido sem diluição continuaram exibindo menor percentual de retenção de ácido ascórbico, com perdas acumuladas de cerca de $68 \%$, resultado semelhante ao obtido na secagem sem DII (63\%) (Figura 8). Os tratamentos com sacarose e açúcar invertido a $41 \%$ apresentaram os menores percentuais de perdas acumuladas (38,6 e 32\%, respectivamente) e os demais tratamentos exibiram valores próximos a 50\%. De acordo com Ferrando e Spiess (2001), a presença de dissaca- rídeos nas células vegetais durante a secagem desempenha importante função, preservando a funcionalidade da membrana celular através da estabilização de fosfolipídios e proteínas. Esta proteção evita danos à membrana plasmática, impedindo a perda de material celular como enzimas e seus respectivos substratos, como a fenolase e o ácido ascórbico, por exemplo, e, conseqüentemente, as reações que afetariam a qualidade sensorial e nutricional do produto durante a etapa de secagem por convecção em ar aquecido. Sendo assim, o tratamento com sacarose a $0,5 \mathrm{~g} \cdot \mathrm{mL}^{-1}$ propiciou maior entrada deste açúcar para o interior das amostras, resultando em menores perdas desta vitamina durante a secagem. Forni et al. (1997) mostraram que damascos desidratados osmoticamente por 120 minutos em solução de sacarose $65 \%$ retiveram mais vitamina $C$ que aqueles desidratados por apenas 45 minutos. Neste mesmo trabalho, a maltose mostrou ser mais efetiva que a sacarose e o sorbitol na manutenção dos níveis de vitamina $\mathrm{C}$ durante a secagem, revelando que o efeito protetor do ácido ascórbico está relacionado ao tipo de carboidrato utilizado na DII.

No armazenamento a $7^{\circ} \mathrm{C}$, o tratamento com açúcar invertido sem diluição se diferenciou significativamente daqueles com sacarose e com açúcar invertido a 41\%, exibindo redução, respectivamente, de 86, 74 e 70\% nos níveis de ácido ascórbico (Figura 8). Os demais tratamentos apresentaram redução de cerca de 70\%. É interessante ressaltar que as amostras secas apenas por convecção apresentaram percentuais de perdas intermediárias (70\%) em relação aos demais tratamentos e não maiores que as amostras pré-tratadas osmoticamente, conforme observado logo depois da secagem. Isto pode ser confirmado pela não significância do C1 e do C2 (Tabela 5). No contraste C3 percebe-se que o açúcar invertido sem diluição proporcionou maior degradação de ácido ascórbico que o açúcar invertido a $41 \%$. Por meio do C4, observa-se mais uma vez a influência da maior concentração de sacarose $\left(0,5 \mathrm{~g} \cdot \mathrm{mL}^{-1}\right)$, melhorando a estabilidade da vitamina $\mathrm{C}$ durante $\mathrm{o}$ armazenamento.

Entretanto, a $25^{\circ} \mathrm{C}$, o efeito de todos os tratamentos foi estatisticamente o mesmo, apresentando níveis de redução entre 70 a $86 \%$ no teor desta vitamina. Observa-se que apenas o C3 (Tabela 5) foi significativo para esta temperatura de armazenamento, mostrando que a maior concentração de açúcar invertido provoca maiores prejuízos nos teores de ácido ascórbico dos pedaços de goiaba. Lima e Durigan (2000), avaliando a conservação de goiabas Pedro Sato, verificaram que a refrigeração proporcionou manutenção de $87 \%$ do teor inicial 
do ácido ascórbico; no entanto, em condições ambientais houve decréscimo de até $64 \%$ em relação ao valor inicial.

Os dados da literatura são conflitantes no que diz respeito à retenção da vitamina $\mathrm{C}$ e concentração da solução osmótica, ao tipo de soluto e à temperatura de armazenamento. Pragati, Dahiya e Dhawan (2003) observaram, logo depois da secagem, maior retenção de ácido ascórbico em frutos de aonla prédesidratados por osmose do que naqueles não previamente osmodesidratados. No entanto, depois de 30,60 e 90 dias de armazenamento à temperatura ambiente, a redução nos teores de vitamina $C$ foi maior nos frutos tratados por DII que nos demais tratamentos (sem DII). Logo, estes autores, assim como este trabalho, observaram superioridade dos produtos osmodesidratados com relação à retenção de ácido ascórbico durante a secagem, mas não no armazenamento. Torreggiani e Bertolo (2001) relataram que os teores de ácido ascórbico foram menores em fatias de kiwi tratadas com solução de $60 \%$ de sacarose em relação às tratadas com maltose, sorbitol ou não tratadas osmoticamente, depois de nove meses de armazenamento a $-10^{\circ} \mathrm{C}$. Entretanto, neste mesmo experimento, as fatias de kiwi não tratadas por osmose mostram teores de ácido ascórbico superiores às demais (tratadas por DII) depois do armazenamento pelo mesmo tempo, porém, a $0{ }^{\circ} \mathrm{C}$ e teores semelhantes a $-20 \mathrm{e}-30^{\circ} \mathrm{C}$.

\section{Conclusões}

- A desidratação por imersão-impregnação de goiabas promoveu redução significativa no teor da maioria dos minerais analisados. O xarope de açúcar invertido foi menos eficiente na manutenção dos teores de minerais, com exceção do K. A solução de sacarose a $0,5 \mathrm{~g} \cdot \mathrm{mL}^{-1}$ provocou maior redução nos teores de $\mathrm{Ke} \mathrm{Mg}$ que a solução de sacarose a 0,3 g.mL $\mathrm{mL}^{-1}$ e maior redução no teor de $\mathrm{Ke}$ menor no de $\mathrm{Zn}$ que a diluição a $0,4 \mathrm{~g} \cdot \mathrm{mL}^{-1}$;

- Houve redução nos teores de vitamina C durante o processamento e armazenamento em todos os tratamentos estudados. A DII com açúcar invertido sem diluição acarretou menor retenção de vitamina C (30\% de perdas) que as soluções de sacarose ( $5 \%$ de perdas) e açúcar invertido a $41 \%$ (10\% de perdas). Não houve diferença significativa entre os efeitos dos solutos sacarose e açúcar invertido quanto à redução de ácido ascórbico ao final da DII;

- A secagem por convecção promoveu perdas significativas de vitamina C, de 32 a $68 \%$, em todos os tratamentos avaliados. As amostras não tratadas osmoticamente apresentaram menor retenção de ácido ascórbico nesta etapa que naquelas submetidas a um dos pré-tratamentos osmóticos; e

- No armazenamento a $7{ }^{\circ} \mathrm{C}$, as amostras pré-tratadas com açúcar invertido sem diluição apresentaram maior percentual de redução de vitamina $\mathrm{C}$ que aquelas prétratadas com sacarose ou com açúcar invertido a $41 \%$. A $25^{\circ} \mathrm{C}$ todos os tratamentos se igualaram estatisticamente, com níveis de redução entre 70 a $86 \%$ nos teores de vitamina $\mathrm{C}$.

\section{Agradecimentos}

Os autores agradecem o apoio técnico e financeiro das seguintes empresas e instituições: Attivos Magisttrais, CNPq, Dulcini Alimentos, FAPERJ, FINEP, Associação de Produtores de Goiaba de Cachoeiras de Macacu - Goiacam e International Foundation for Science - IFS.

\section{Referências bibliográficas}

A.O.A.C. - Association of Official Analytical Chemists. Official methods of analysis. $15^{\text {th }}$ edition. Arlington, 1990.

ARAUJO, F. et al. Crecimiento y acumulación de nutrientes del fruto de Guayaba (Psidium guajava L.) del tipo "Criolla Roja” en la planicie de Maracaibo. Revista de la Facultad de Agronomía - LUZ, Maracaibo, v. 14, p. 315-328, 1997.

AZZOLINI, M.; JACOMINO, A. P.; BRON, I. U. Índices para avaliar qualidade pós-colheita de goiabas em diferentes estádios de maturação. Pesquisa Agropecuária Brasileira, Brasília, v. 39, n. 2, p. 139-145, 2004.

BOLIN, H. R. et al. Effect of osmotic agents and concentration on fruit quality. Journal of Food Science, v. 48, n. 1, p. 202-205, 1983.

BRODY, T. Nutritional Biochemistry. San Diego: Academic Press, 1994. $658 \mathrm{p}$.

CHITARRA, M. I. F; CHITARRA, A. B. Pós-colheita de frutos e hortaliças: Fisiologia e manuseio. Lavras: Esal/FAEPE, 1990. 293 p.

DALLA ROSA, M.; GIROUX, F. Osmotic treatments (OT) and problems related to the solution management. Journal of Food Engineering, v. 49, n. 2-3, p. 223-236, 2001.

DERMESONLOUOGLOU, E. K.; GIANNAKOUROU, P. T. Stability of dehydrofrozen tomatoes pretreated with alternative osmotic solutes. Journal of Food Engineering, v. 78, n. 1, p. 272-280, 2007.

DURIGAN, J. F. Colheita, conservação e embalagens. In: SIMPÓSIO BRASILEIRO SOBRE A CULTURA DA GOIABEIRA, 1., Jaboticabal, 1997. Anais... Jaboticabal: FUNEP, p. 152-154.

ERLE, U.; SCHUBERT, H. Combined osmotic and microwave vacuum dehydratiom of apples and strawberries. Journal of Food Engineering, v. 49, n. 2-3, p. 193-199, 2001.

FELLOWS, P. Tecnología del processado de los alimentos: Princípios y prácticas. Zaragoza: ACRIBIA, 1994. 549 p.

FERRANDO, M.; SPIESS, W. E. L. Cellular response of plant tissue during the osmotic treatment with sucrose, maltose, and trehalose solutions. Journal of Food Engineering, v. 49, n. 2-3, p. 115-127, 2001.

FORNI, E. et al. The influence of sugar composition on the colour stability of osmodehydrofrozen intermediate moisture apricots. Food Research International, v. 30, n. 2, p. 87-94, 1997.

FRANCO, G. Tabela de Composição Química dos Alimentos. $2^{\mathrm{a}}$. ed. Rio de Janeiro: Atheneu, 2001. 307p.

GORINSTEIN, S. et al. Comparative content of total polyphenols and dietary fiber in tropical fruits and persimmon. The Journal of Nutritional Biochemistry, v. 10, n. 6, p. 367-371, 1999.

HARDISSON, A. et al. Mineral composition of the banana (Musa acuminata) from the island of Tenerife. Food Chemistry, v. 73, n. 2, p. 153-161, 2001.

HENRY, C. J. K.; MASSEY, D. Crop Post-Harvest Programme. Food Science and Nutrition Research Group. School of Biological and Molecular Sciences Micro-nutrient changes during food processing and storage. Oxford: Oxford Brookes University, 
2001. Disponível em: <http://www.cphp.uk.com/downloads/ issue_paper_5.Pdf $>$. Acesso em: 11 maio 2005.

HENRY, C. J. K.; HEPPELL, N. Nutritional losses and gains during processing: future problems and issues. Proceedings of the Nutrition Society, Cambridge, v. 61, n. 1, p. 145-148, 2002.

HOBSON, G. E.; DAVIES, J. N. The tomato. In: HULME, A. C. The biochemistry of fruits and their products. New York: Academic Press, 1971. v. 1. p. 437-481.

I.O.M. - Institute of Medicine of The National Academy Of Sciences. Dietary Reference Intake (DRI). Food and Nutrition Board. Washington: National Academy Press, 1999. Disponível em: <http:// www.nap.edu>. Acesso: 11 jan. 2006.

KHRAISHEH, M. A. M.; McMinN, W. A. M.; MAGEE, T. R. A. Quality and structural changes in starchy foods during microwave and convective drying. Food Research International, v. 37, n. 5, p. 497-503, 2004.

KREŠIĆ, G.; LELAS, V.; ŠIMUNDIĆ, B. Effects of processing on nutritional composition and quality evaluation of candied celeriac. Sādhanā, v. 29, n. 1, p. 1-12, 2004.

LAZARIDES, H. N. Osmotic Preconcentration: Developments and Prospects. In: SINGH, R. P.; OLIVEIRA, F. A. R. (Eds.) Minimal processing of foods and process optimization. An Interface. Boca Raton: CRC Press, 1994. p. 73-85.

LIMA, D. M. et al. Tabela brasileira de composição de alimentos/ NEPA-UNICAMP. T113 Versão II. Campinas: NEPA-UNICAMP, 2006. 105 p. Disponível em: <http:/www.unicamp.br/nepa/taco>. Acesso em: 29 jul. 2006.

LIMA, M. A.; DURIGAN, J. F. Conservação de goiabas Pedro Sato associando-se refrigeração com diferentes embalagens. Revista Brasileira de Fruticultura, Jaboticabal, v. 22, n. 2, p. 232-236, 2000.

MAHAN, K.M.; ESCOOTT-STUMP, S. Krause: Alimentos, Nutrição \& Dietoterapia. 10. ed. São Paulo: ROCA, 2002. 1157 p.

MARCY, J. E.; HANSEN, A. P.; GRAUMILCH, T. R. Effect of storage temperature on the stability of aseptically packaged concentrated orange juice and concentrated orange drink. Journal of Food Science, v. 54, n. 1, p. 227-228, 1989.

PADH, H. Vitamin C: newer insights into its biochemical functions. Nutrition Reviews, v. 49, n. 3, p. 65-70, 1991.

PADULA, M.; RODRIGUEZ-AMAYA, D. B. Characterisation of the carotenoids and assessment of the vitamin A value of Brazilian guavas (Psidium guajava L.). Food Chemistry, v. 20, n. 1, p. 11-19, 1986.

PEIRÓ, R. et al. Micronutrient flow to the osmotic solution during grapefruit osmotic dehydration. Journal of Food Engineering, v. 74, n. 3, p. 299-307, 2006.

PEIRÓ-MENA, R.; CAMACHO, M. M.; MARTÍNEZ-NAVARRETE, N. Compositional and physicochemical changes associated to successive osmodehydration cycles of pineapple (Ananas comosus). Journal of Food Engineering, v. 79, n. 3, p. 842-849, 2006.

PEREIRA, L. M. et al. Vida-de-prateleira de goiabas minimamente processadas acondicionadas em embalagens sob atmosfera modificada. Ciência e Tecnologia de Alimentos, Campinas, v. 23, n. 3, p. 427-433, 2003.

PRAGATI, S. D.; DHAWAN, S.S. Effect of drying methods on nutritional composition of dehydrated aonla fruit (Emblica officinalis Garten) during storage. Plant Foods for Human Nutrition, v. 58, p. 1-9, 2003.

PREGNOlatTO, W.; PREGNOlatTO, N. P. (Coord.) Normas analíticas do Instituto Adolfo Lutz. Métodos químicos e físicos para análise de alimentos. 3. ed. São Paulo: INSTITUTO ADOLFO LUTZ, 1985.

QUEIROZ, V.A.V. Teores de Na, K, Ca, Mg, Fe, Zn, Cu e Se em frutas consumidas na região Norte Fluminense. Campos dos Goytacazes, 2004, 73 p. Dissertação (Mestrado em Produção Vegetal), Universidade Estadual do Norte Fluminense Darcy Ribeiro (UENF).

RAOULT-WACK, A. L. Recent advances in the osmotic dehydration of foods. Trends in Food Science \& Technology, v. 5, n. 8, p. 255-260, 1994.

RICHARDSON, T. I. L.; BALL, L.; ROSENFELD, T. Will an orange a day keep the doctor away? (Case Report). Postgraduate Medical Journal, v. 78, n. 919, p. 292-294, 2002.

RIVA, M. et al. Structure-property relationships in osmo-airdehydrated apricot cubes. Food Research International, v. 38, n. 5, p. 533-542, 2005.

SANCHEZ-CASTILLO, C. P. et al. The mineral content of Mexican fruits and vegetables. Journal of Food Composition and Analysis, v. 11, n. 4, p. $340-356,1998$.

TORREGGIANI, D. Osmotic dehydration in fruit and vegetable processing. Food Research International, v. 26, n. 1, p. 59-68, 1993.

TORREGGIANI, D.; BERTOLO, G. High-quality fruit and vegetable products using combined processes. In: FITO, P. (Ed) Osmotic dehydration e vacuum impregnation. Lancaster: Technomic Publishing Company, 2001. cap. 1. p. 3-9.

Osmotic pre-treatments in fruit processing: chemical, physical and structural effects. Journal of Food Engineering, v. 49, n. 2-3, p. 247-253, 2001.

UDDIN, M. S. et al. Degradation of ascorbic acid in dried guava during storage. Journal of Food Engineering, v. 51, n. 1, p. 21-26, 2002.

VIKRAM, V. B.; RAMESH, M. N.; PRAPULLA, S. G. Thermal degradation kinetics of nutrients in orange juice heated by electromagnetic and conventional methods. Journal of Food Engineering, v. 69, n. 1, p. 31-40, 2005. 